\title{
Teachers and Creativity: The Role of Internal Motives
}

\author{
Nikolaos Theodoropoulos ${ }^{1} \&$ Pandelis Kiprianos, ${ }^{1, *}$ \\ ${ }^{1}$ Department of Early Childhood Education, University of Patras, Rion, Patras, Greece \\ *Corresponding author: Department of Early Childhood Education, University of Patras, \\ Rion, Patras, Greece. E-mail: nicktheo29@gmail.com
}

Received: May 22, 2020 Accepted: July 6, 2020 Published: September 25, 2020

doi:10.5296/ije.v12i3.17746

URL: https://doi.org/10.5296/ije.v12i3.17746

\begin{abstract}
In this paper we investigate whether and to what extent teachers' values function as internal motives that shape their involvement with innovation and Innovative Programs. Linking Amabile's theoretical schema with Super's concept of work values, our aim is to detect the features of this shaping. The research has a dual aim: on the one hand to examine the extent to which teachers are receptive to innovation and Innovative Programs and on the other, to analyze the role played in this by work and educational values. From our research it emerged that the more the teachers are governed by the values of offering something, autonomy and sociocentric relationships with colleagues, the more likely is their involvement with educational innovation.
\end{abstract}

Keywords: creativity, internal motives, innovation, education, teachers 


\section{Introduction}

Teacher-centered teaching, mechanical rote-learning of school books, the difficulty of linking school knowledge to the pupils' everyday experience and the predominance of the 'tutorial schools' as the solution that ensures school success, are just some of the commonly accepted illnesses of Greek education. The fundamental issues that educational policies designed to cure these weaknesses are based on, are creativity and innovation.

Especially in terms of the teachers, motivation, both internal and external, for creative practices, is attributed to factors such as the organizational culture of creativity, the psychology that governs work relationships, the degree of involvement in work identity and the social influences that shaped the worker's values. Leaving to one side its conceptualizations as a product of some 'charismatic personality', researchers believe that creativity is related to problem solving processes, to the way one locates problems, poses research questions and suggests means of solving them that were initially considered unusual but which in time are adopted as self-evident (Brewer and Gardner 1996). Within this context, Glaveanu (2010) believes that there are three dimensions to creativity: a) the socio-cultural nature of the creative acts and the interdependence between the individual and the environment, b) the role played by dialogue and interpersonal relationships in the process of the production of creative ways of thinking and c) the way in which the team processes challenges and problems that arise in the environment.

Our research focuses on the subjective dimension of creativity, on the motivation and values of the teachers that influence it. We believe that motivation and values comprise the chief factors shaping the teachers' attitudes towards the introduction of Innovative Programs (IP) and that they determine the quality of the programs' implementation. The main idea that runs through the theoretical approach and the methodological design of the research is the shift of interest from the 'obstacles' in the analysis of subjective logics that contextualize the attitude adopted by the teacher in the implementation of IP.

The reason for the shift in emphasis from the study of obstacles to the investigation of values is dual. We leave to one side the behaviorist claim that governs the studies of barriers, which at times explicitly and at others implicitly, are founded on the idea that if we change the external factors that make the application of IP difficult, then the quality of their implementation will change too. At the same time, focusing on their value system, we study the teachers not cut off from their environment but as integrated into real social relationships and situations through which their values are shaped. In this way, the 'environment' is not confronted as a mere 'external obstacle', or as a 'stimulus' in behaviorist terminology, but as a constituent through which the teachers' attitude to IP and the logic of creativity they express, takes shape.

\section{State of Art}

Research on the factors that cancel out the culture of innovation usually separate the stumbling blocks into two categories, the 'internal' barriers and the 'external'. Integrated into 
the first are the school tradition, the culture of the school, and the teachers' attitude to change. In the second there is bureaucracy, the cost and lack of resources. The common ground of these approaches is a) that innovation that is seen as an order from above has no chance of success unless the teachers are convinced of its value and b) that when the teachers don't expect innovation in education to constitute an organic part of teaching, they have no reason to invest in it (Kiprianos \& Theodoropoulos 2017; Guile, 2003).

We find features of this approach in the research of Hofman et al. (2012), who investigated the questions a) what shape do innovations take; b) are there types of innovation that are linked to the quality of school; and c) what are the effects of the innovations on the school career of the students? One of the interesting conclusions is that there appears to be a positive relationship between innovations and school success, since the schools where innovative teaching methods had been introduced into the curriculum and the teacher-student relationship, had better school performances and a higher rate of satisfaction amongst their students. Nevertheless, the authors point out that school effectiveness is not a simple countable, determined by its students' performances, but is manifest in the passion its students show for learning and in the development of post-cognitive skills (Hofman et al. 2012).

Papert (1997) proposes the examination of the relationship between the adoption of innovation and the resistance to change in an attempt to highlight the contextual nature of innovation and the gradual change that is on the way for the whole of the school and organizational culture through its adaptation to new practices. In this context, for some researchers, the distinction between 'first' and 'second' degree barriers is important. The first concern chiefly the environment into which the innovation is introduced, and factors such as the lack of resources, time, and training, while the second focus exclusively on the beliefs and attitudes of the teachers, that is to say, they concern the cognitive, emotional and volitional factors that make up the reasons and motivations that discourage someone from adopting innovative practices. Such could be a lack of trust, a negative attitude to change, the noticeable feeling that the innovation will be of no benefit (Ertmer 1999).

Jones (2004) has claimed that teachers tend to adopt innovation only when they are completely convinced of its practical results or only when it helps them to do better what they already know. In terms of that, a decisive factor in this attitude is the kind of pedagogical theories the teacher supports and the picture he has of the effective teacher. In contrast, the first degree barriers have a more organizational background and have more frequently been the target of bureaucratic and administrative interventions. In any case, the majority of the research reveals that a deeper understanding of the factors inhibiting innovation requires a combination of institutional and individual dimensions which hinder its application (Becta, 2009, Kable, 2009).

Research that has focused on the external dimension of innovation has highlighted the necessity of the networking of the school unit as a prerequisite for a successful application of innovation. Networking that is favourable for innovation could be the development of bonds such as with the regional university, voluntary organizations or nonprofit citizen movements 
(e.g. some scientific institute), which can help not only the exchange of technological knowledge relating to innovation, but also means for supporting it. At the same time such kinds of support that the community provides also favour the concentration of those resources that are necessary for the acceptance of innovation by the institutional bodies that surround the school (Sharma 2005).

According to Lundvall et al (2008) the culture of innovation should give priority to social skills (cooperation, communication, empathy...) since such a culture is instrumental in a school open to the community, supportive of the interdisciplinary approach to knowledge and a learning process founded on problem solving.

The abovementioned researchers point out that the highlighting of barriers (institutional, or individual) should be combined with the context and the particular features of each case within which teachers and students interact (Kiprianos \& Theodoropoulos, 2017). These interactions are organized on the basis of various thematic levels or, as they are called, 'levels of influence'. Their thinking is that on every thematic level different kinds of barriers predominate which hinder the application of innovation. The merit of this type of approach to the matter is that in this way light is shone on the nature and characteristics of the various barriers with greater accuracy.

Drawing mainly on Bronfenbrenner's theory, Cox et al. (1999) have distinguished four thematic levels which function to either facilitate or obstruct innovation: a) factors concerning the innovation itself, b) factors concerning the teachers' attitudes and the relationships that they have developed with their pupils, c) factors linked to school culture and the relationships that the school has with the wider community and d) factors linked to the kind educational policy that is developed in relation to innovation and the formation of the curriculum. On the basis of this schema, on the one hand, the relationships between the levels of influence are highlighted, as well as their relationships with the kind of first and second degree barriers that we mentioned earlier.

Fullan (1991) summarizes the features that frame the application of innovation into 3 categories: (a) the features of change which include the determined or distinct necessity, clarity, degree of complexity, quality, the possibility of implementation, (b) the features of the region, which include the region, classification, the role of the headmaster and the teacher, and (c) external factors. The prerequisite for the effectiveness of innovation is energy and participation at the beginning of the action, pressure and support, connection of theory and practice, adoption of the action. Hence, if one wants to locate the factors that reduce the chances of the introduction of innovation, these are related to the fear that perhaps weaknesses will be revealed, they constitute a source of insecurity and concern about the unknown it brings, interests are affected, it brings about an increase in the workload, pressure as well perhaps as conflict, it creates common interest groups and so on. Consequently, change is not likely to succeed, if it is not promoted and directed, without taking all factors into account.

To summarize the above, a significant role in the successful outcome of an innovation, is played by the teachers. They should be suitably prepared, both theoretically and practically, 
and be practiced in the means that make up the innovations (Ryan \& Joong 2005). In addition, the teachers' relationships with each other constitute a weighty factor in the success of the introduction of innovation. The teachers share common working conditions and coexist, having developed amongst themselves bonds capable of confronting the problems that emerge during the implementation of innovative action (Sergiovanni 2001). The teachers' collaborative relationships can strengthen the development of the skills that are essential for innovation, since each teacher hasn't reached the same degree of readiness alone that is required for its application (Fullan 2005).

In recent research Brundrett and Duncan (2011) claim that beyond the above, the success of innovation depends on the curriculum that sets out its chief epistemological beliefs. For the curriculum oriented towards innovation to succeed, they claim, the members of the teaching community should be convinced of its necessity, have adopted its educational values, be actively involved not only in the application but in its conception, so that it is adapted to the needs and givens of the local culture that frame the school. The prerequisite for all of this, they conclude, is the prior conduct of evaluative research which will have set out the sectors that the innovation is aimed at.

\section{Contribution of the Research}

We can extract two observations from a review of the bibliography. The successful introduction and implementation of innovation is more likely the less the teachers experience it as an institutional order, produced from on high, the faithful implementation of which could transform the school. On the contrary, innovation is perceived of as a continual request that traverses the whole of the educational relationship, from teaching and professional development to the organizational culture.

Consequently, research on innovation should focus on the way in which the structural dimensions are intertwined with the regulative, which facilitate or cancel out its implementation within a given educational context. This point is the basis from which our research begins. We don't focus, as much other related qualitative research does, on the external barriers to innovation. The problem with this approach lies in the fact that it leads to a 'black box' logic ignoring the action and the subjective meaning of those involved, first and foremost the teachers. Appointing external barriers as reasons for the unsuccessful implementation of IP, eliminates the processes through which teachers approach the IP and organize their interventions.

This research comes in answer to the question of the content of the 'black box' placing at the centre of its problematic, the subjective factor as the intermediary link between external or institutional situations and practical applications of innovation. In the light of this theoretical perspective, it poses questions and forms explanatory schemata that can not only simply describe the data, but comprehend and interpret them too. In other words, examining the beliefs and values of the teachers regarding the parameters that frame the educational environment in which the application of innovation unfolds, we will have a better picture of 
the ways in which the external condition of innovation interacts with its subjective reception and use.

\section{Objective and Research Questions}

The aim of our research is the investigation of the representations of primary and secondary school teachers in Western Greece (Achaia region) in relation to a) the implementation, b) the design and c) the evaluation of IP. Through this triple focus, we investigate whether and why teachers judge IP to be necessary, whether and to what extent they are familiar with the culture of innovation, and finally what they hope for from the implementation of IP.

We endeavored to transform the research objectives into specific research questions so as to etch out the corresponding response strategy. The research questions that we attempt to answer are the following:

1) What are the teachers' views on what innovation in education is and in which areas do they think it is necessary/useful?

2) What are the reasons that push teachers to participate in the implementation of IP, or not?

3) How do the teachers' values influence their decisions regarding participation in IP?

4) Finally, what kind of IP do teachers implement?

\section{Theoretical Framework: Amabile's Model for Creativity and Internal Motives}

Our research is approached from the perspective of internal motivation. For this reason, it is founded on one of the most important contributions as far as the relationship between internal motivation and innovation is concerned, the contribution of Amabile (1990a). Her model favours certain criteria for the promotion of institutional innovation, which have a direct relationship with the educational innovation that we are concerned with here. The definitions of creativity focus on the features of personality or the extent to which its result is useful.

Amabile forms a model for creativity which is founded on three axes (Amabile 1983). These are skills related to the object, skills related to creativity and internal motivation. The first axis refers to possession of the required skills in a sector or profession. With the skills in the first axis, we process potential responses to a problem. However, this is not enough. We also need to have a positive attitude to risk, social skills and specialized cognitive skills such as a willingness to experiment with new ideas so as to reflect on the obvious and the surprising. The third axis is considered the most important, internal motivation. Even if the requirements of the first two axes are not met, internal motivation can make up for them. It is the difference between what people do and what people can do.

The three axes of the model of creativity define how one handles information so as to arrive at a solution. Internal motivation plays a great role in the whole process and the search for a solution. The skills related to a particular area of interest determine the cognitive routes that 
we will follow and the criteria we will choose in order to consider possible solutions. The skills, finally, that are related to creativity itself control the very process of execution. We should note that one's knowledge of an area of interest is not as important as ease of access to its categories and the way in which they are related.

An important parameter that we shouldn't forget is the way we react to the result of our effort to carry out our professional duty. In the case of complete success, we won't have the motivation to perform the same duty due precisely to this complete success. Internal motivation will increase only in the case where the next duty resembles the previous one. On the other hand, complete success reduces internal motivation. In the case of partial success, internal motivation increases only when we feel satisfied with this small success while motivation will disappear when we realize that we are far away from solving the problem.

Creativity, consequently, requires internal motivation and a work context that favors the quest for creative solutions to problems. On the other hand, we can't completely ignore external motivation since work and institutional rules are those that ensure that a professional duty will be completed on time. Nor can we ignore the fact that we want recognition and financial reward for our work. Research has shown that some people are creative when there have external motivation and restrictions (Amabile et al., 1994).

From the bibliographical discussion on creativity we believe that two ideas concern our research directly. Firstly, creativity is a kind of experience that is related to the subjective condition of the individual, and how much he enjoys being involved with something. It is an idea that is directly dependent on the individual's personal values. Secondly, internal motivation plays a decisive role not only in the production of innovative thought and action, but also in the collective well-being of the workplace. These two ideas lead to the observation that the individual's value system is also a decisive factor which influences his relationship with his work environment.

Starting from this position on the role of values, we believed that Super's studies $(1963,1970$, and 1973) are significant for the investigation of the correlation of values with the choice of profession and professional satisfaction. According to him, the practical importance of work values lies in the fact that they influence the means that a society uses to manage its economic activity. Work values have a causal relationship with the personal meanings that people attribute to their work. They influence choice of work and career path, as we are driven to activities compatible with our work values (Super 1995). In other words, work values function as motivation for involvement in the world of work. This is reflected in use of time. For Super, people's ability to manage time in terms of a plan to be implemented depends on early and clear information giving, interaction with key individuals in the environment and their personal interests.

From the discussion so far it emerges that work values influence not only the criteria for choosing a profession but also the kind of involvement the individual will have with his work. The main dimension of this influence highlights the contribution of work values to whether and to what extent workers will get involved in innovative and creative activities. The more the individual's personal values are in line with the values of the work environment within 
which he works, then the greater his job satisfaction (O’Reilly et al.,1991).

In our paper we adopt this idea. We also believe that the individual's values are strengthened by his work environment. In practice this means that whether and how the teacher gets involved in the implementation of creative activities in school depends on the net of values that make up his individual and collective personality. As we pointed out, beyond the relationship between the values system and job satisfaction, work values are closely linked to work culture (Ehrhart \& Makransky 2007; Kalliath et al. 1999; Smith and Campbell 2006).

The majority of the research on this problematic applies Super's $(1970,1973)$ Work Values Inventory (WVI), the validity of which is frequently tested. From a number of measurements it appears that the WVI continues to maintain high levels of internal validity, something that is strengthened by the fact that it has been used in non-Western countries (Shia \& Youe, 1983). In our research we adopted the inventory in question. It is made up of 39 statements, grouped into four thematic axes: 'central values', 'work environment', 'relationships with colleagues' and 'work activities'. Each of the four axes contains 8 - 10 statements which are divided into two different semantic units. Indicatively, the thematic axis of questions 'central values' includes 9 statements, 4 of which make up the semantic unit 'offer' and the other 5 the semantic unit 'autonomy'. These units emerged from our reconstruction based on a bibliographical review. The thematic unit 'work environments' contains 8 statements, 4 of which comprise the semantic unit 'flexible working environments' and the other 4 make up the semantic unit 'inflexible working environments'. The thematic unit 'relationships with colleagues' contains nine (9) statements, three (3) of which make up the semantic unit 'individual-centered relationships' and the remaining six (6) constitute the semantic unit 'sociocentric relationships'. Finally, the thematic unit 'work activities' does not contain any sub-groups.

Super's questionnaire was translated from English into Greek by two Drs in Sciences of Education in collaboration with one of the authors of this article. The first translation was given to three observers. Based on their comments, we came up with a second version. It was translated into English again by two translators with a very good knowledge of English. Based on their text, we came up with a third version in Greek. The final questionnaire was used in our pilot research.

\section{Methodology}

The methodology followed was based exclusively on the use of the questionnaire. Applying stratified sampling, 450 questionnaires were distributed to 450 Primary and Secondary School teachers in the Achaia region, 250 in secondary and 200 in primary education, (the former number 2,392 and the latter 1,600, so 3,992 teachers in total).

In the first part of the questionnaire the measurement scale of the teachers' values, which emerged from the combination of Amabile's theory on internal motivation and Super's concept of work values, is presented. In the other parts, the measurement scales that emerged aim at the depiction of the uptake of innovation by teachers, the necessity of it and the 
reasons for which they either participate, or don't participate in IP.

For detecting the statistically significant correlations and the effects of values on innovation we adopted the Pearson Chi-Square and the Multiple Linear Regression Analysis. For the needs of the research we applied the Cronbach test. To test the validity, we applied content validity through our pilot research. For this purpose, we distributed the second version of the questionnaire to twenty (20) educators, $\mathrm{PhDs}$ holders, $\mathrm{PhD}$ candidates and master's degree holders. Through the validity test we significantly improved the statements mainly on the scale for measuring the values of teachers.

\section{Findings: The Influence of Values in Educational Innovation}

From the analysis it emerged that values function as internal motives through which teachers assign meaning to the uptake of innovative actions. First of all, the uptake of the usefulness of educational innovation is influenced by the importance assigned to the concept of 'offer'. The more the teachers believe that 'offering' is important in their life, the more likely they are to agree that innovation is very useful in education. A second value that has a decisive effect is 'autonomy'. The more the teachers believe that it is important in their life, the more likely they are to claim that they agree that innovation is useful (Koutsianou, \& Emvalotis, 2019). Finally, the more the teachers believe that 'sociocentric' relationships with their colleagues are important in their life, the more likely they are to believe that innovation is necessary in education.

As far as the sample is concerned, we observed two noteworthy differentiations. The first concerns the level of education. Primary education teachers agree with most of the statements on the scale, while in contrast the secondary education teachers seemed more reluctant and often unwilling to agree with them. The former appeared more open to innovation as we defined it in the questionnaire especially as far the link between school and society, school performance, inter-school collaboration and the cultivation of democratic values are concerned.

The second differentiation has to do with the specialization. We observed that the primary and secondary school teachers who held a degree in the Sciences of Education and the Social Sciences agreed to a greater degree with most of the statements on the scale that concern the usefulness of innovation. In contrast, the holders of degrees in Humanities and the Sciences are either ambivalent or negative towards most of the statements.

Nevertheless, these two differentiations do not alter our chief finding, that is to say, the importance of internal motivation for creativity in the way Amabile analyses it.

From the data analysis it emerged that teachers are receptive to innovation much more as something linked to the sociocentric dimension of learning (ensuring the participation of the pupil in school activities and social interactions, collaboration amongst students and understanding of concepts in a lived way) and much less as a practice linked to pupil performance or the learning of a cognitive object, whether we see that traditionally (as a 
demarcated cognitive field) or in more contemporary terms (in other words as a field of interdisciplinary knowledge). This seemed to depend on their value system and especially the emphasis they place on values such as 'offering something', 'autonomy', 'creativity' and 'sociocentric' relationships with colleagues.

The influence of values in whether teachers participate or not in IP is tangible and is worthy of particular emphasis. To make this more clear we drew up two tables, based on regression analysis, which illustrate which of the values in our research present statistically significant effects for each of the reasons for participation (table 1) and non-participation (table 2).

Table 1. Summary of the Statistically Significant Influences of Values and Reasons for Participation in Innovative Programs

\begin{tabular}{|c|c|c|c|c|c|c|c|c|}
\hline & $\begin{array}{l}\text { Because I } \\
\text { like to } \\
\text { experiment } \\
\text { with new } \\
\text { pedagogica } \\
1 \text { methods }\end{array}$ & $\begin{array}{l}\text { To } \\
\text { improve } \\
\text { my } \\
\text { knowledge } \\
\text { in a } \\
\text { cognitive } \\
\text { area }\end{array}$ & $\begin{array}{l}\text { To increase } \\
\text { the chances } \\
\text { of my } \\
\text { professional } \\
\text { development }\end{array}$ & $\begin{array}{l}\text { To examine a } \\
\text { problem or a } \\
\text { phenomenon in } \\
\text { an } \\
\text { interdisciplinary } \\
\text { way }\end{array}$ & $\begin{array}{l}\text { Because } \\
\text { it is } \\
\text { good for } \\
\text { the } \\
\text { image } \\
\text { of the } \\
\text { school }\end{array}$ & $\begin{array}{l}\text { Because } \\
\text { it is } \\
\text { necessar } \\
\text { y to } \\
\text { make up } \\
\text { my } \\
\text { working } \\
\text { hours }\end{array}$ & $\begin{array}{l}\text { Because } \\
\text { it } \\
\text { improves } \\
\text { my CV }\end{array}$ & $\begin{array}{l}\text { Because } \\
\text { it } \\
\text { improves } \\
\text { the } \\
\text { pupils' } \\
\text { social } \\
\text { skills }\end{array}$ \\
\hline Creativity & $\mathrm{V}$ & $\mathrm{V}$ & $\mathrm{V}$ & $\mathrm{V}$ & $\mathrm{V}$ & $X$ & $\mathrm{~V}$ & $\mathrm{~V}$ \\
\hline $\begin{array}{l}\text { Inflexible } \\
\text { environmens }\end{array}$ & $X$ & $X$ & $\mathrm{~V}$ & $X$ & $\mathrm{~V}$ & V & $\mathrm{V}$ & $X$ \\
\hline $\begin{array}{l}\text { Offering } \\
\text { something }\end{array}$ & $\mathrm{V}$ & $\mathrm{V}$ & $\mathrm{X}$ & V & $X$ & $X$ & $X$ & V \\
\hline Autonomy & V & $\mathrm{V}$ & $\mathrm{V}$ & V & V & V & V & $\mathrm{X}$ \\
\hline $\begin{array}{l}\text { Sociocentric } \\
\text { relationships }\end{array}$ & V & $\mathrm{V}$ & $\mathrm{X}$ & $\mathrm{V}$ & $X$ & $X$ & $X$ & V \\
\hline
\end{tabular}

In table 1 it is evident that the values of 'autonomy' and 'creativity' have a great influence on the way in which teachers cite reasons for participation in IP. This finding confirms Amabile's theory according to which one requirement for the successful introduction of innovation is the positive attitude to risk, social skills, lack of prejudices and willingness to experiment with new ideas aimed at reflection on what is taken as given and what is considered unusual.

We could suppose that if one teacher embraces the value of 'autonomy' that is to say, he considers the values 'I am in control of my choices and it is not that others decide for me', 'to be able to influence others' or 'to have an effect on others' to be significant, then he cites only external motivation to become involved in innovative actions. This hypothesis is refuted by our research which leads once more to internal motivation.

The value of 'creativity' has a statistically significant influence as much on the internal as on the external motivation in the reasons behind participation. The more the teachers in the 
sample embrace the value of creativity (where the project requires creativity and imagination to produce a result, requires risk, interpretation and processing of data and information or involves innovative products or projects), the more likely the teachers are to agree as much with the internal motivation for participation in IP (such as 'I participate in order to examine an issue in an interdisciplinary way') as with the external motivation related to reasons for participation in IP such as 'I participate in order to improve my work hours'.

This finding, in our opinion, debunks a simplifying theorization of creativity according to which this is related only to internal motivation (George 2007, Auger \& Reynaud 2008). On the contrary, from our research it emerges that creativity coexists with the external parameters related to the institutional organization of work, such as the structure of opportunities for professional development. In table 1 we observe that internal motivation is also influenced by the values 'sociocentric relationships with colleagues' and 'offering something'. The external motivation is influenced, in contrast, only by the value 'inflexible work environment'. This finding is significant because it reveals that the more the teacher considers it very important that his work should bring him money, be predictable and have a clear time frame, the more likely he is to cite only external motivation as a reason for participating in IP. On the other hand the more he embraces the values of 'offering something' and believes it is very important that his relationships with his colleagues have a sociocentric basis, the more likely he is to cite only internal motivation for participating in IP.

Table 2. Summary of the Statistically Significant Influences of Values and Reasons for NON Participation in Innovative Programs

\begin{tabular}{|c|c|c|c|c|c|c|}
\hline & $\begin{array}{l}\text { Because } \\
\text { getting } \\
\text { through } \\
\text { the } \\
\text { syllabus } \\
\text { takes } \\
\text { priority }\end{array}$ & $\begin{array}{l}\text { Because I } \\
\text { don't think } \\
\text { that } \\
\text { innovative } \\
\text { programs } \\
\text { improve } \\
\text { some aspect } \\
\text { of the } \\
\text { teacher's } \\
\text { work (e.g. } \\
\text { teaching, } \\
\text { pedagogy) }\end{array}$ & $\begin{array}{l}\text { Due to } \\
\text { lack of } \\
\text { personal } \\
\text { free time }\end{array}$ & $\begin{array}{l}\text { Because it } \\
\text { doesn't offer } \\
\text { opportunities } \\
\text { for } \\
\text { professional } \\
\text { development }\end{array}$ & $\begin{array}{l}\text { Because in } \\
\text { general I don't } \\
\text { like to } \\
\text { experiment } \\
\text { with } \\
\text { pedagogical } \\
\text { methods with } \\
\text { uncertain } \\
\text { results }\end{array}$ & $\begin{array}{l}\text { Because } \\
\text { there isn't } \\
\text { enough } \\
\text { institutional } \\
\text { and } \\
\text { economic } \\
\text { support }\end{array}$ \\
\hline $\begin{array}{l}\text { Offering } \\
\text { something }\end{array}$ & $\mathrm{X}$ & $\mathrm{X}$ & $\mathrm{V}$ & $\mathrm{V}$ & $\mathrm{X}$ & $\mathrm{X}$ \\
\hline Autonomy & $\mathrm{X}$ & $\mathrm{X}$ & $\mathrm{X}$ & V & $\mathrm{X}$ & V \\
\hline $\begin{array}{l}\text { Inflexible } \\
\text { environments }\end{array}$ & V & V & $\mathrm{V}$ & V & V & V \\
\hline $\begin{array}{l}\text { Sociocentric } \\
\text { relationships }\end{array}$ & $\mathrm{X}$ & $\mathrm{X}$ & $\mathrm{X}$ & $\mathrm{X}$ & V & $\mathrm{X}$ \\
\hline Creativity & $\mathrm{X}$ & V & $\mathrm{V}$ & $\mathrm{X}$ & V & $\mathrm{V}$ \\
\hline
\end{tabular}


Table 2 illustrates the statistically significant influences on the reasons for nonparticipation in IP. Here too the influence of the values is evident. More specifically, the more the teacher believes that it is very important to work in an environment where his work will earn him money or in which one knows what is going to happen every day, the more likely he is to cite various reasons for not participating in the implementation of IP. This finding is in our opinion explained by Amabile's theory according to which the success of innovation requires, among other things, a flexible work environment in the context of which creativity is encouraged on a collective and institutional level. It is not by chance then that the reason given for non-participation, of 'getting through the school syllabus takes priority' is related in a statistically significant way to the reason in question.

The lack of free time as a reason for choosing non-participation in IP is significant only for those who embrace the value of 'offering something' and 'creativity - self-expression'. This means that for those teachers who want to become involved in creative actions because they place great value on being able to offer something, and creativity, the lack of free time is of decisive importance.

The teachers that believe the value of autonomy is very important, cite reasons for non-participation in IP related to professional development and scanty institutional and economic support. Finally, for the teachers who assign great value to creativity, non-participation in IP is attributed, beyond the lack of personal free time, to doubts they have over whether and to what extent these improve some aspect of their pedagogical work.

This finding does not confirm the research of Hofman et al. (2012) according to which teachers who participate in innovative programs are driven by strictly scientific and pedagogic reasons such as improving pupils' knowledge and school performance.

Our research also showed that many teachers, especially in secondary education, consider the lack of ties with local communities as the reason for their non-participation in the innovative programs. This confirms findings of relative research (Hopkins et al. 1997; Sharma 2005) which revealed that synergies between school and local communities contribute positively to the taking of innovative action.

\section{Conclusions}

Internal motivation in Amabile's sense is closely linked to creativity and innovation. Their influence on the way we become involved in educational innovation is tangible. From the data analysis it follows that teachers are receptive to innovation more as something linked to the sociocentric dimension of learning (ensuring the participation of the pupil in school activities and social interactions, collaboration amongst students and understanding of concepts in a lived way) and less as a practice linked to pupil performance or the learning of a cognitive subject, whether we see that as a distinct cognitive field or in more modern terms as a field of interdisciplinary knowledge. This seemed to depend on their value system and especially the emphasis they place on values such as 'offering something', 'autonomy', 'creativity' and 'sociocentric' relationships with colleagues. 
There are certainly differences in the involvement of the teachers in our sample. These are linked with the level of education and the study object. Primary education teachers, especially those who graduated from Educational Sciences University Departments, and those in secondary education who studied Social Sciences, seem to be affected more by the culture of creativity and innovation than the others. This probably depends on the university studies and in particular the curriculum and teaching methods.

Consequently, initial education is important in the shaping of values which as internal motivators determine the quality of involvement with educational innovation. This means the highlighting of the necessity for the epistemology of creativity as a philosophical basis for the organization of studies at university to be further supported, not only within the departments of educational sciences and social studies, but in all.

From the two conclusions above we are led to a third which concerns the drawing up of educational policy. This ought to take into account not only the institutional barriers and external rewards but the subjective factors too. It should take into account the perspective and internal motivation of the teachers so that they are more creative and innovative. In conclusion, creativity as a means of organizing the educational process goes together with the development of a culture within the context of which teachers consider self-agency and innovation as integral.

Our research has certain limitations. It concerns an area where teachers lag behind their colleagues in other areas in certain qualifications such as in-service time, and possession of postgraduate and doctoral degrees. This means that our sample is not representative of the body of Greek teachers.

\section{References}

Amabile, T. M. (1983). The social psychology of creativity. New York: Springer-Verlag. http://doi.org/10.1007/978-1-4612-5533-8_1

Amabile, T. M. (1990). Within you, without you: Toward a social psychology of creativity, and beyond. In Runco, M. A., and Albert, R. S. (Eds.), Theories of Creativity. Newbury Park, CA: Sage.

Amabile, T. M., Hill, K. G., Hennessey, B. A., \& Tighe, E. M. (1994). The work preference inventory: Assessing intrinsic and extrinsic motivational orientations. Journal of Personality and Social Psychology, 66, 950-967. http://doi.org/10.1037/0022-3514.68.4.580

Auger, P., \& Reynaud, E. (2008). Le trio valeur traditionnelle, innovation, confiance: l'enseignement de deux cas opposés, pompiers et industrie aéronautique. Gestion 2000, $25,55-80$.

Becta. (2009). Harnessing Technology: Business practices which support risk-taking and innovation in schools and colleges. Retrieved from http://dera.ioe.ac.uk/id/eprint/1536 
Brewer, M. B., \& Gardner, W. (1996). Who is this 'we'? Levels of collective identity and self-representations. Journal of Personality and Social Psychology, 71(1), 83-93. http://doi.org/10.1037/0022-3514.71.1.83

Brundrett, M., \& Duncan D. (2011). Leading curriculum innovation in primary schools. Management in Education, 25(3), 119-124. http://doi.org/10.1177/0892020610387957

Cox, M., Preston, C., \& Cox, C. (1999). What factors support or prevent teachers from using ICT in the primary classroom. British Educational Research Association Annual. Conference, Retrieved September, 2-5, 1999 from http://www.leeds.ac.uk/educol/documents/00001304.htm

Ehrhart, K. H., \& Makransky, G. (2007). Testing vocational interests and personality as predictors of person-vocation and person-job fit. Journal of Career Assessment, 15, 206-226. http://psycnet.apa.org/doi/10.1177/1069072706298105

Ertmer, P. (1999). Examining teachers' beliefs about the role of technology in the elementary classroom. Journal of Research on Computing in Education, 32(1), 54-72. http://doi.org/10.1080/08886504.1999.10782269

Fullan, M. (2005). The new meaning of educational change (3rd ed). London: Routledge-Falmer.

Fullan, M. (1991). The new meaning of educational change. London: Cassel.

George, J. M. (2007). Creativity in organizations. Academy of Management Annals, 1, 439-477. http://doi.org/10.5465/078559814

Glâveanu, V. P. (2010). Principles of a Cultural Psychology of Creativity. Culture \& Psychology, 16(2), 147-163.

Guile, D. (2003). From 'Credentialism' to the 'Practice of Learning': reconceptualising learning for the knowledge economy. Policy Futures in Education, 1(1), 83-105. http://doi.org/10.2304/pfie.2003.1.1.10

Hopkins, D., Ainscow, M., \& West, M. (1997). School Improvement in an Era of Change. London: Cassell.

Hofman, R. H., Boom, J., Meeuwise, M., \& Hofman, W. H. A., (2012). An Exploration of Innovations and Their Effects in Primary Education. Educational Policy, 27(6), 843-866. http://doi.org/10.1177/0895904811429288

Jones, A. (2004). A Review of the Research Literature on Barriers to the Uptake of ICT by Teachers. Becta.

Kable, G. (2009). Models for Innovation in Education. Becta.

Kalliath, T. J., Bluedorn, A. C., \& Strube, M. J. (1999). A test of value congruence effects. Journal of Organizational Behaviour, 20, 1175-1198.

Kiprianos, P., \& Theodoropoulos, N. (2017). Innovation in education: The social 
representations and practices of Greek teachers. Sociology International Journal, 1(4), 141-146. http://doi: 10.15406/sij.2017.01.00024

Lundvall, B., Rasmussen, P., \& Lorenz, E. (2008). Education in the Learning Economy: European perspective. Policy Futures in Education, 6(6), 681-700. http://doi.org/10.2304/pfie.2008.6.6.681

O'Reilly, A. C., Chatman, J., \& Caldwell, F. D. (1991). People and organizational culture: A profile comparison approach to assessing person-organization fit. Academy. http://doi.org/10.5465/256404

Papert, S. (1997). Barriers to school innovation. The Journal of the Learning Sciences, 6(4), 417-427.

Ryan, T., \& Joong, P. (2005). Teachers and Students Perception of the Nature and Impact of Large-Scale Reform. Canadian Journal of Educational and Administration Policy, 38, 42-50. http://cdm.ucalgary.ca/index.php/cjeap/article/view/42718

Sergiovanni, Th. (2001). Leadership. What's in it for schools? London: Routledge and Falmer.

Sharma, R. (2005). Identifying a Framework for Initiating, Sustaining and Managing Innovations in Schools. Psychology and Developing Societies, 17(1), 51-80. http://doi.org/10.1177/097133360501700104

Shia, L. C., \& Youe, H. C. (1983). The work value interest inventory: An introduction and revision report. Test and Guidance, 60, 1030-1036.

Smith, T. J., \& Campbell, C. (2006). The structure of O*NET occupational values. Journal of Career Assessment, 14(4), 437-448.

Super, D. E. (1963). Career development. Self-concept theory. New York: Academic Press.

Super, D. E. (1970). Manual, Work Values Inventory. Chicago: Riverside Publishing Company.

Super, D. E. (1973). The work value inventory. In D. G. Zytwoski (Ed.), New approached to interest measurement (pp. 189-205). Minneapolis, MN: University of Minnesota Press.

Super, D. E. (1995). Values: Their nature, assessment, and practical use. In D. E. Super, B. Sverko, \& C. Super (Eds.), Life roles, values, and careers: International findings of the work importance study. San Francisco: Jossey Bass, 55-61.

\section{Copyright Disclaimer}

Copyright for this article is retained by the author(s), with first publication rights granted to the journal.

This is an open-access article distributed under the terms and conditions of the Creative Commons Attribution license (http://creativecommons.org/licenses/by/3.0/). 